\title{
Complementary foods in baby food pouches: position statement from the Nutrition Commission of the German Society for Pediatrics and Adolescent Medicine (DGKJ, e.V.)
}

\author{
Berthold Koletzko ${ }^{1 *}$, Christoph Bührer ${ }^{2}$, Regina Ensenauer ${ }^{3}$, Frank Jochum ${ }^{4}$, Hermann Kalhoff ${ }^{5}$, Burkhard Lawrenz ${ }^{6}$, \\ Antje Körner ${ }^{7}$, Walter Mihatsch ${ }^{8}$, Silvia Rudloff ${ }^{9}$ and Klaus-Peter Zimmer ${ }^{9}$
}

\begin{abstract}
Pureed complementary feeding products packed in squeezable plastic pouches, usually with a spout and a screw cap, have been increasingly marketed. The Committee on Nutrition recommends that infants and young children should not suck pureed or liquid complementary foods from baby food pouches. Complementary foods should be offered with a spoon or should be fed as finger foods. Infants and young children should be given the opportunity to get to know a variety of foods and food textures including pieces of foods, supported by responsive feeding between the child and their parents or caregivers. Complementary foods marketed in baby food pouches often have a high energy density and are predominantly extremely high in sugar content, with up to almost $90 \%$ of the total energy content. Regular consumption bears the risks of imbalanced nutrient provision and increased risks for dental caries and overweight. Complementary foods for infants and young children should have a balanced composition following the recommendations of the German Society of Pediatrics and Adolescent Medicine (DGKJ) and should contain only limited amounts of sugar. We discourage the feeding of pureed complementary foods from baby food pouches.
\end{abstract}

Keywords: Complementary feeding, Sugars, Energy density, Nutrient requirements, Eating behavior, Parent-child interaction, Infant feeding

Breastfeeding is the optimal form of infant feeding, with numerous health benefits for mother and child [1-3]. Between the beginning of the fifth and the beginning of the seventh month of life, complementary foods should be introduced in addition to breastfeeding. Complementary foods provide additional energy and critical nutrients such as iron, zinc, iodine, B vitamins, and long-chain polyunsaturated fatty acids (LC-PUFA) to support normal growth and development [1-3]. Complementary foods, including

\footnotetext{
* Correspondence: Berthold.Koletzko@med.uni-muenchen.de

This consensus paper will simultaneously be published in German in Monatsschrift Kinderheilkunde, the official organ of the German Society of Pediatrics and Adolescent Medicine (DGKJ).

'Div. Metabolic and Nutritional Medicine, Dept. of Pediatrics, Dr. von Hauner Children's Hospital, University Hospital, LMU - Ludwig-Maximilians-Universität Munich, Munich, Germany

Full list of author information is available at the end of the article
}

homemade or commercially available complementary foods for infants and young children, can be offered.

In recent years, there has been a rapid and increasing number and variety of pureed foods for infants and young children available on the market which are packed in compressible plastic bags and are usually equipped with a spout and a screw cap (so-called baby food pouches) [4]. Some products even have a spoon that can be screwed on and refilled directly from the baby food pouch. Based on the total volume, these products are often twice as expensive as conventional baby food fruit jars. However, from the point of view of many parents, baby food pouches offer a simple and convenient approach to complementary feeding. After unscrewing the screw cap, the food pouch contents can be squeezed directly into the mouth of the infant or the young child, 
or the child can suck or drink the contents from the food pouch spout, in the case of low-viscosity products like "smoothies." In this way, mealtimes at home or on the road can be quick and easy. This type of complementary feeding has become very popular. Even reusable baby food pouches are sold, which allow infant feeding with pureed homemade complementary foods.

This type of complementary feeding may seem attractive for parents because it is perceived as time-saving and convenient; however, it raises serious concerns $[5,6]$. The complementary feeding period is not only important for the provision of nutrients but it also serves as a time of transition from an exclusive milk diet to a diet of diversified family foods, with gradual learning of differentiated oropharyngeal movements and the development and shaping of eating behaviors $[7,8]$. When infants receive complementary foods primarily through sucking foods from baby food pouches, this may delay or hinder learning to eat from a spoon or learning to eat finger foods [9]. The exploration of foods with the lips, tongue, and the hands as well as the practice of chewing can be impaired. Some observational studies indicate a potentially limited window of opportunity for favorable introduction of solid foods. For example, the delayed introduction of chunky foods after the age of about 9 to 10 months was associated with increased feeding difficulties and low intake of vegetables and fruits at later ages [10]. It, therefore, seems inadvisable to give infants and young children complementary foods which are mostly in semi-liquid or pureed consistency and which are predominantly consumed through sucking.

Moreover, if infants and young children are given a variety of textures and pieces of solid foods with a spoon or through feeding themselves by hand, it offers an opportunity for intense interaction between parents and children. This allows for mutual listening and dialog with the child, and for the monitoring and learning of hunger signals and sensitive responses (responsive feeding) $[11,12]$. These opportunities can be wasted if children are allowed to suck complementary foods from a baby food pouch alone.

The typical composition of baby food pouches raises serious concerns. Product claims that are perceived positively by parents are often brought to the forefront, for example, natural or organic ingredients, the absence of artificial additives, gluten, or lactose, or the vegetarian or vegan characteristics of the product. However, many of these products have a high energy density, a very sweet taste, and a totally unbalanced nutritional composition with sugar contents that are too high. On the 13th and 14th of October 2018, a non-systematic and non-exhaustive internet search was carried out. The nutrient composition of 100 complementary food products offered in baby food pouches in Germany for infants and young children with an age indication: after the 4th month, from the 6th month, or from the 12th month of age were recorded (Additional file 1: Table S1). The search showed energy contents between 38 and 89 $\mathrm{kcal} / 100 \mathrm{~g}$ product (median $60 \mathrm{kcal} / 100 \mathrm{~g}$; 75th percentile $66 \mathrm{kcal} / 100 \mathrm{~g}$; 90th percentile $75 \mathrm{kcal} / 100 \mathrm{~g}$ ) and sugar contents between $40.0 \%$ and $88.9 \%$ of energy content $(\mathrm{E} \%)$ (median $70.1 \mathrm{E} \%$; 75th percentile $78.7 \mathrm{E} \%$; 90th percentile $83.3 \mathrm{E} \%$ ). Baby food pouches on offer contain predominantly sweet pureed fruit preparations. Even products with the claim of the content of cereals, vegetables, or dairy products are very sweet and have too high a sugar content. The 20 products with the highest energy content from sugar are shown in Table 1.

Complementary food products, which consist exclusively or predominantly of sweet fruit preparations, are not recommended as meals [1-3]. They not only contribute to high sugar intakes, which are questionable for health, but they also do not provide relevant quantities of critical nutrients that should be provided in addition to breastfeeding, in particular iron, zinc, iodine, B vitamins, and long-chain polyunsaturated fatty acids (LC-PUFA). In order to enable the child to get to know a variety of aromas and flavors, fruit should be offered as part of fruit-cereal porridges or offered separately after a diverse meal made up of vegetables, meat, or fish.

Pureed foods with high sugar content tend to adhere to tooth surfaces more so than chewed foods with abrasive properties and may therefore present an increased risk of developing dental caries [13-15]. This is especially true when these products are sucked out of the packaging and expose tooth enamel over an extended period of time. The combination of very high sugar content and organic fruit acids suggests an additional increase in caries risk.

There is also an indication that children who are regularly exposed to very sweet foods may experience potential long-term effects on their taste preferences and food choices. In observational studies, a high intake of sweet foods and drinks early on is associated with a higher preference for sweet foods in later life [16]. This is undesirable because of the associations between high intakes of sweet foods and the increased risk for dental caries, obesity, and associated non-communicable diseases [17].

For parents, giving a baby food pouch to their child with pureed fruit may seem equivalent to giving fresh fruit, but this is not the case. The high energy density in many complementary food products sold in baby food pouches is far higher than the typical energy density of fresh fruit (for example, $54 \mathrm{kcal} / 100 \mathrm{~g}$ apple). The extremely high sugar content in most products makes them unsuitable for feeding infants and young children. The high sugar content seems to come from the preferred use of very sweet fruit varieties and the addition 
Table 1 Top 20 complementary foods sold in baby food pouches with the highest sugar and percent energy from sugar ( $\mathrm{g} / 100 \mathrm{~g}$ and \% energy content). In a non-systematic internet research on 13th and 14th of October 2018, a total of 100 baby food pouches with the age recommendations: after the 4th month, from the 6th month onwards, and after the 12th month were recorded (see Additional file 1: Table S1)

\begin{tabular}{|c|c|c|c|}
\hline Product & $\begin{array}{l}\text { Energy } \\
\mathrm{kcal} / 100 \mathrm{~g}\end{array}$ & $\begin{array}{l}\text { Sugar } \\
\mathrm{g} / 100 \mathrm{~g}\end{array}$ & $\begin{array}{l}\text { Sugar } \\
\% \text { kcal }\end{array}$ \\
\hline Sesame Street baby food pouch Elmo 100\% apple, banana, and raspberry & 63 & 14 & 88.9 \\
\hline Bebivita baby food pouch of pear raspberry in apple & 49 & 10.5 & 85.7 \\
\hline Bebivita baby food pouch Squeeze Me! kiwi banana in apple & 56 & 12 & 85.7 \\
\hline Hipp baby food pouch Super Hippis pomegranate acerola in apple raspberry & 50 & 10.6 & 84.8 \\
\hline Erdbaer Freche Freunde baby food pouch $100 \%$ apple, pear, and passion fruit & 52 & 11 & 84.6 \\
\hline Hipp baby food pouch Hippis peach in apple mango & 55 & 11.5 & 83.6 \\
\hline Holle Baby food pouch apple and mango & 58 & 12.1 & 83.4 \\
\hline MOGLi baby food pouch fruit drink banana rhubarb raspberry & 71 & 14.8 & 83.4 \\
\hline Hipp baby food pouch Hippis wild berries in apple peach & 49 & 10.2 & 83.3 \\
\hline Hipp baby food pouch Hippis wild berries in apple peach & 49 & 10.2 & 83.3 \\
\hline Holle baby food pouch apple with carrot and parsnip & 49 & 10.2 & 83.3 \\
\hline Erdbaer Freche Freunde baby food pouch $100 \%$ apple, strawberry, blueberry, and raspberry & 43 & 8.9 & 82.8 \\
\hline Alete baby food pouch dragon fire strawberry banana & 65 & 13.4 & 82.5 \\
\hline Hipp baby food pouch smoothie mix blueberry in apple pear & 54 & 11.1 & 82.2 \\
\hline Hipp baby food pouch smoothie mix red fruits in apple banana & 61 & 12.5 & 82.0 \\
\hline Hipp baby food pouch Hippis strawberry banana in apple & 54 & 10.9 & 80.7 \\
\hline Hipp baby food pouch Hippis strawberry banana in apple & 54 & 10.9 & 80.7 \\
\hline Holle baby food pouch apple and banana & 66 & 13.3 & 80.6 \\
\hline Erdbaer Freche Freunde baby food pouch 100\% apple, banana, spinach, and cucumber & 50 & 10 & 80.0 \\
\hline DM organic baby food pouch banana-orange-beetroot & 60 & 12 & 80.0 \\
\hline
\end{tabular}

of fruit juice concentrates, such as apple juice concentrate or grape juice concentrate or concentrated fruit preparations. Typically, the majority or even all of the sugar content comes from the fruit preparation used and not from added sugars, so that even products with extremely high sugar are labeled "no sugar added." This claim may falsely create the impression with families that products are low in sugar, which may also lead to other family members, including siblings, to more regularly consume products. Not only "added sugar" but, above all, the total sugar content is responsible for undesirable effects on child health, such as adverse metabolic effects, high insulin secretion, increased risk for tooth decay, obesity, and other diseases.

The combination of a high energy density of these extremely sugar-rich products together with the ease of absorption by sucking the pureed product can result in a much higher energy and sugar intake-predominantly in the form of fructose-in a short time frame when compared to chewing and swallowing pieces of fruit. The very high sugar intake from a meal of pureed fruit preparation can be expected to significantly increase blood sugar and insulin levels compared to the consumption of fresh fruit. This is because the matrix of an intact fruit will usually lead to a slower sugar absorption than with a pureed preparation. For example, mashed potatoes had a much higher glycemic index (83) compared to cooked potatoes (49) [18]. A high glycemic index and a high glycemic load stimulate increased insulin secretion in children and can promote undesirable high weight gain and increased body fat deposition [19]. When regularly feeding infants and young children with fruit purees from baby food pouches, an increased risk of overfeeding and excessive weight gain must be expected, which is associated with a significantly increased risk for later obesity [20-22]. A high habitual sugar intake has also been associated with an increased, obesity-associated risk of cancer [23]. The birth cohort study Project VIVA in New England showed poorer cognitive performance (Kaufman Brief Intelligence Test II) with a high sugar intake in pregnancy and early childhood at $3-8$ years of age [24].

Different fruits differ in their sugar contents and composition. In general, however, fruits are rich in fructose, and they also contain variable amounts of glucose and sucrose [25]. In many of the pureed fruit preparations, the fructose content is further increased, for example, by the addition of apple juice concentrate. With a high fructose intake from pureed fruit preparations, adverse 
metabolic effects are to be expected. A high fructose intake promotes de novo lipogenesis, fatty liver, and the occurrence of non-alcoholic fatty liver disease [26-28]. An important role of fructose intake is also supported by the findings of a study of 302 children with fructose malabsorption, who could only receive a limited amount of fructose and had a significantly lower frequency of obesity (2.3\%) compared to a control group of children of the same age without limited fructose intake (6.1\%) [29]. An increased risk for asthma has also been reported to be induced by fructose [30]. Although further investigations are needed to elucidate the pathophysiological and health effects of the various dietary sugars [31], currently available data suggest that sugar intake should ideally be below $5 \%$ of energy intake and in any case not exceed $10 \%$ of energy intake $[17,32]$.

Some baby food pouches have small screw caps as prescribed by the requirements of the European safety regulations for toys (EN 71), which are not legally binding for food packaging. However, there is a potential hazard for infants and young children due to the possibility of choking on small caps.

\section{Conclusion}

Infants and toddlers should not suck pureed or liquid foods out of baby food pouches. Much more, infants and young children should be given the opportunity to get to know a variety of foods through spoon-feeding and by eating finger foods by hand. This should be supported through responsive feeding between the parent or caregiver and the child. It is recommended to feed home-prepared, balanced composite foods with a low sugar content and high content of vital nutrients such as iron, zinc, iodine, B vitamins, and long-chain polyunsaturated fatty acids, according to current recommendations [1-3]. These foods should offer a variety of taste and textures. If commercial complementary foods are used, they should be comprised and selected according to the same principles. Industrial fruit purees should not replace entire meals, but only be part of a meal (for example, in a fruit-cereal porridge) or be offered as a complement to a meal. Giving complementary foods in the form of drinks is not recommended. Pureed foods should be fed with a spoon and not be sucked out of food pouches.

\section{Additional file}

Additional file 1: Table S1. Sugar and energy content (g/100 g product and $\%$ of energy content) in 100 complementary foods marketed as baby food pouches with the age recommendations: after the 4th month, from 6th month, and from the 12th month, sorted by sugar content (\% of energy). Data from a non-systematic internet search on 13th and 14th of October 2018. (DOCX 31 kb)

\section{Abbreviations}

DGKJ: German Association for Pediatrics and Adolescent Medicine; EN 71: European standard specification 71, safety regulations for toys; LCPUFA: Long-chain polyunsaturated fatty acids; LMU: Ludwig-MaximiliansUniversität München

\section{Acknowledgements}

Not applicable

Funding

Not applicable

Availability of data and materials

See Table 1

Authors' contributions

All authors contributed equally to the script. All authors read and approved the final manuscript

Ethics approval and consent to participate

Not applicable

Consent for publication

Not applicable.

\section{Competing interests}

The Ludwig-Maximilians-Universität München and its employee BK were supported by financial support from the Commission of the European Communities (FP5-QLRT-2001-00389 CHOPIN, FP5-QLAM-2001-00582 PIANO, FP6007036QLRT-2001-00389 EARNEST, FP7-289346-EarlyNutrition), the European Research Council (Grant ERC-2012 AdG-no.322605 META-GROWTH), the European Joint Programming Initiative NutriProgram ERA-HDHL, the European Erasmus + programs Early Nutrition eAcademy Southeast Asia-573651-EPP-12016-1-EN-EPPKA2-CBHE-JP and Capacity Building to Improve Early Nutrition and Health in South Africa-598488-EPP-1-2018-1-EN-EPPKA2-CBHE-JP, and the European Interreg- Program Focus in CD-CE111. Additional funding was provided by the Federal Ministry of Education and Research (no. $01 \mathrm{Gl} 0825$ and INST 409/224-1 FUGG), the German Research Foundation (KO912/10-1), the McHealth innovation initiative of the LMU and the LMU Center for Advanced Studies. LMU and its employee BK have collaborated with pharmaceutical and food companies on scientific and educational projects, mostly as part of publicly funded research projects. None of these interactions have affected the content of this manuscript.

CB's employer received fee equivalent payments from the Nestlé Nutrition Institute for lectures. RE received grants for talks by Ferring and Milupa. FJ has received funding for lecture and training activities from Fresenius, Baxter, Human, HIPP, Nestlé. The FJ employer is involved in research/clinical trials of Fonterra and Humana.

HK has received financial contributions from Abbvie for lectures. $\mathrm{BL}$ has received financial contributions from Abbvie, BVKJ-Service $\mathrm{GmbH}$, Engelhard, GSK, Hansisches Verlagskontor, KVWL Consult, Life Sciences, Medice, MSD, Novartis, Pfizer, Product + Market, RG, Sanofi Pasteur, and SPMSD. AK has received financial grants from Ipsen Pharma.

WM has received grants from Nestlé, Nutricia, and Nutrinia.

SR does not indicate any potential conflicts of interest.

The employer of $\mathrm{PZ}$ receives grants from the BMBF for the BMBF study CED. All authors do not declare a conflict of interest under the guidelines of the US Institute of Medicine.

\section{Publisher's Note}

Springer Nature remains neutral with regard to jurisdictional claims in published maps and institutional affiliations.

\section{Author details}

${ }^{1}$ Div. Metabolic and Nutritional Medicine, Dept. of Pediatrics, Dr. von Hauner Children's Hospital, University Hospital, LMU - Ludwig-Maximilians-Universität Munich, Munich, Germany. ${ }^{2}$ Clinical Center for Neonatology, Charité Universitätsmedizin Berlin, Berlin, Germany. ${ }^{3}$ Clinical Center for Paediatrics, Neonatology and Paediatric Cardiology, Center for Paediatrics and Adolescent Medicine, University Medical Center Düsseldorf, Research Institute of Child Nutrition, Max Rubner-Institut Karlsruhe, Düsseldorf, Germany. 
${ }^{4}$ Waldkrankenhaus Protestant Hospital Berlin Spandau, Berlin, Germany. ${ }^{5}$ Hospital for Paediatrics and Adolescent Medicine Dortmund, Dortmund, Germany. ${ }^{6}$ Private Practice for Paediatrics and Adolescent Medicine, Arnsberg, Germany. ${ }^{7}$ Paediatric Research Center, Clinical Center and Polyclinic for Paediatrics and Adolescent Medicine, Department for Gynecology and Paediatrics, University Medical Center Leipzig, Leipzig, Germany. ${ }^{8}$ Children's Hospital Heliosclinic Pforzheim, Pforzheim, Germany. ${ }^{9}$ Center for Paediatrics and Adolescent Medicine, Justus-Liebig-University Gießen, Giessen, Germany.

Received: 20 February 2019 Accepted: 21 February 2019 Published online: 06 March 2019

\section{References}

1. Prell C, Koletzko B (2016) Breastfeeding and complementary feedingrecommendations on infant nutrition. Dtsch Arztebl Int 113(25):435-344

2. Ernährungskommission_der_Deutschen_Gesellschaft_für_Kinderheilkunde_ und_Jugendmedizin-(DGKJ-e.V.), Bührer C, Genzel-Boroviczény O, Jochum F Kauth T, Kersting M et al (2014) Ernährung gesunder Säuglinge. Empfehlungen der Ernährungskommission der Deutschen Gesellschaft für Kinder- und Jugendmedizin. Monatsschr Kinderheilkd 162:527-538

3. Koletzko B, Bauer CP, Cierpka M, Cremer M, Flothkötter M, Graf C et al (2016) Ernährung und Bewegung von Säuglingen und stillenden Frauen. Aktualisierte Handlungsempfehlungen von "Gesund ins Leben-Netzwerk Junge Familie", eine Initiative von IN FORM. Monatsschr Kinderheilkd. 164(9): 771-798

4. Verbraucherzentrale-Niedersachsen. 2014 [Available from: https://www. verbraucherzentrale-niedersachsen.de/themen/ernaehrung-lebensmittel/ kinderlebensmittel-der-quatsch-den-quetschies. Accessed 2 Mar 2019.

5. Koletzko B, Hirsch NL, Jewell JM, Caroli M, Breda J, Weber M (2018) Pureed fruit pouches for babies_child health under squeeze. J Pediatr Gastroenterol Nutr. https://doi.org/10.1097/MPG.0000000000002061

6. Theurich MA (2018) Perspective: novel commercial packaging and devices for complementary feeding. Adv Nutr 9(5):581-589

7. ESPGHAN-Committee-on-Nutrition FM, Bronsky J, Campoy C, Domellof M, Embleton $\mathrm{N}$ et al (2017) Complementary feeding: a position paper by the European Society for Paediatric Gastroenterology, Hepatology, and Nutrition (ESPGHAN) Committee on Nutrition. J Pediatr Gastroenterol Nutr 64(1):119-132

8. Simione M, Loret C, Le Reverend B, Richburg B, Del Valle M, Adler M et al (2018) Differing structural properties of foods affect the development of mandibular control and muscle coordination in infants and young children. Physiol Behav 186:62-72

9. Cichero JAY (2017) Unlocking opportunities in food design for infants, children, and the elderly: understanding milestones in chewing and swallowing across the lifespan for new innovations. J Texture Stud 48(4): 271-279

10. Coulthard H, Harris G, Emmett P (2009) Delayed introduction of lumpy foods to children during the complementary feeding period affects child's food acceptance and feeding at 7 years of age. Matern Child Nutr 5(1):75-85

11. Hetherington MM (2017) Understanding infant eating behaviour-lessons learned from observation. Physiol Behav 176:117-124

12. Silva GA, Costa KA, Giugliani ER (2016) Infant feeding: beyond the nutritional aspects. J Pediatr 92(3 Suppl 1):S2-S7

13. Kaewkamnerdpong I, Krisdapong S (2018) The associations of school oral health-related environments with oral health behaviours and dental caries in children. Caries Res 52(1-2):166-175

14. Paglia L, Scaglioni S, Torchia V, De Cosmi V, Moretti M, Marzo G et al (2016) Familial and dietary risk factors in early childhood caries. Eur J Paediatr Dent 17(2):93-99

15. Evans EW, Hayes C, Palmer CA, Bermudez OI, Cohen SA, Must A (2013) Dietary intake and severe early childhood caries in low-income, young children. J Acad Nutr Diet 113(8):1057-1061

16. Beauchamp GK, Mennella JA (2011) Flavor perception in human infants: development and functional significance. Digestion. 83(Suppl 1):1-6

17. ESPGHAN-Committee-on-Nutrition, Fidler Mis N, Braegger C, Bronsky J, Campoy C, Domellof M et al (2017) Sugar in infants, children and adolescents: a position paper of the European Society for Paediatric Gastroenterology, Hepatology and Nutrition Committee on Nutrition. J Pediatr Gastroenterol Nutr 65(6):681-696
18. World-Health-Organisation (2016) Guidance on ending the inappropriate promotion of foods for infants and young children. Report to the 69th World Health Assembly. World Health Organisation, Geneva

19. Socha P, Hellmuth C, Gruszfeld D, Demmelmair H, Rzehak P, Grote V et al (2016) Endocrine and metabolic biomarkers predicting early childhood obesity risk. Nestle Nutr Inst Workshop Ser 85:81-88

20. Rzehak P, Oddy WH, Mearin ML, Grote V, Mori TA, Szajewska H et al (2017) Infant feeding and growth trajectory patterns in childhood and body composition in young adulthood. Am J Clin Nutr 106(2):568-580

21. Oddy WH, Mori TA, Huang RC, Marsh J, Pennell C, Jacoby P et al (2014) Early infant feeding and adiposity risk: from infancy to adulthood. Ann Nutr Metab 64:215-223

22. Geserick M, Vogel M, Gausche R, Lipek T, Spielau U, Keller E et al (2018) Acceleration of BMI in early childhood and risk of sustained obesity. N Engl J Med 379(14):1303-1312

23. Makarem N, Bandera EV, Lin Y, Jacques PF, Hayes RB, Parekh N (2018) Consumption of sugars, sugary foods, and sugary beverages in relation to adiposity-related cancer risk in the Framingham offspring cohort (19912013). Cancer Prev Res (Phila) 11:347-358

24. Cohen JFW, Rifas-Shiman SL, Young J, Oken E (2018) Associations of prenatal and child sugar intake with child cognition. Am J Prev Med 54(6): 727-735

25. Ma C, Sun Z, Chen C, Zhang L, Zhu S (2014) Simultaneous separation and determination of fructose, sorbitol, glucose and sucrose in fruits by HPLCELSD. Food Chem 145:784-788

26. Schwarz JM, Noworolski SM, Erkin-Cakmak A, Korn NJ, Wen MJ, Tai WW et al (2017) Effects of dietary fructose restriction on liver fat, de novo lipogenesis, and insulin kinetics in children with obesity. Gastroenterology. 153:743-752

27. Sekkarie A, Welsh JA, Vos MB (2018) Carbohydrates and diet patterns in nonalcoholic fatty liver disease in children and adolescents. Curr Opin Clin Nutr Metab Care 21(4):283-288

28. Tappy L (2018) Fructose metabolism and noncommunicable diseases: recent findings and new research perspectives. Curr Opin Clin Nutr Metab Care. 21(3):214-222

29. Disse SC, Buelow A, Boedeker RH, Keller KM, Kim-Berger HS, Wudy SA et al (2013) Reduced prevalence of obesity in children with primary fructose malabsorption: a multicentre, retrospective cohort study. Pediatr Obes 8(4): 255-258

30. DeChristopher $L R$, Tucker $K L$ (2018) Excess free fructose, high-fructose corn syrup and adult asthma: the Framingham offspring cohort. Br J Nutr 119(10):1157-1167

31. Herman MA, Samuel VT (2016) The sweet path to metabolic demise: fructose and lipid synthesis. Trends Endocrinol Metab 27(10):719-730

32. World Health Organisation (2015) Sugars intake for adults and children. World Health Organisation, Geneva

\section{Submit your manuscript to a SpringerOpen ${ }^{\odot}$ journal and benefit from:}

- Convenient online submission

- Rigorous peer review

- Open access: articles freely available online

- High visibility within the field

- Retaining the copyright to your article

Submit your next manuscript at $>$ springeropen.com 